\title{
Cervical Disc Replacement: A Systematic Review of Medline Indexed Literature
}

\author{
Sudarshan Munigangaiah, John P. McCabe \\ Spine Service, Department of Trauma and Orthopaedic Surgery, Galway University Hospitals, Galway, Ireland. \\ Email: drsudarshan79@gmail.com
}

Received April 25 ${ }^{\text {th }}$ 2013; revised May 30 ${ }^{\text {th }}, 2013$; accepted June $10^{\text {th }}, 2013$

Copyright (C 2013 Sudarshan Munigangaiah, John P. McCabe. This is an open access article distributed under the Creative Commons Attribution License, which permits unrestricted use, distribution, and reproduction in any medium, provided the original work is properly cited.

\begin{abstract}
Anterior Cervical Discectomy and Fusion (ACDF) currently remains as the gold standard treatment for cervical disc herniation and Degenerative Disc Disease (DDD) refractory to conservative management. Even though anterior cervical fusion provides excellent clinical results, it has been implicated in abnormal kinematic strain on adjacent disc level resulting in symptomatic adjacent segment disease. Anterior cervical disc replacement (ACDR) is an alternative procedure to anterior cervical discectomy and fusion. The aims of cervical disc replacement were to preserve the motion at the index level and to protect the adjacent levels from accelerated symptomatic degeneration. The aim of this systematic review was to evaluate the outcomes of cervical disc replacement published in MEDLINE indexed literature. A literature search was carried out in medical electronic database MEDLINE. Keywords used for the search were Cervical vertebrae, Cervical spine, Neck, Intervertebral disc, Total disc replacement, Arthroplasty, Replacement, Treatment outcome. Two authors reviewed titles and abstracts of all two hundred and thirty six hits. The articles that satisfied the inclusion criteria were critically appraised while remaining articles were discarded. Anterior cervical disc replacement is a relatively new technology in spinal surgery. There are several short and intermediate term follow-up studies to prove the safety and efficacy of ACDR with satisfactory clinical and radiological outcomes. More intermediate to long-term follow-up studies are needed to prove the safety and efficacy of ACDR.
\end{abstract}

Keywords: Cervical Vertebrae; Cervical Spine; Neck; Intervertebral Disc; Total Disc Replacement; Arthroplasty; Replacement; Treatment Outcome

\section{Introduction}

Cervical disc degeneration happens to be a normal ageing process. However, in some individuals it could be debilitating because of compression of the nerve root and/or spinal cord causing cervical radiculopathy and/or myelopathy respectively [1]. Anterior Cervical Discectomy and Fusion (ACDF) currently remains the standard treatment for disc herniation and Degenerative Disc Disease (DDD) refractory to conservative management. ACDF has been the gold standard treatment for a long time [2]. Robinson and Smith [3] first described anterior cervical discectomy and fusion. Anterior cervical discectomy and fusion converts a motion segment unit into a fused segment without any movement at the index motion segment. Even though anterior cervical fusion provides excellent clinical results, it has been implicated in abnormal kinematic strain on the adjacent disc level $[4,5]$.
Increased stress on adjacent disc level to the fused level was thought to lead to accelerated disc degeneration resulting in symptomatic adjacent disc disease [5-7].

In a study involving a total of 374 patients, $2.9 \%$ of patients per annum required reoperation for symptomatic adjacent segment disease after anterior cervical discectomy and fusion [7]. Same study also showed that 25\% of patients who had undergone anterior cervical discectomy and fusion developed new symptoms adjacent to the fused level with 10 years of index surgery. Potential morbidities of cervical fusion included decreased cervical range of motion, pseudoarthrosis, graft donor site morbidity and instrumentation related complications [813] that led to thinking towards an alternative procedure like anterior cervical disc replacement (ACDR). To overcome the limitations of anterior cervical discectomy and fusion, like symptomatic adjacent segment disease due to increased motion and strain at adjacent level, disc re- 
placement was introduced. The aim of cervical disc replacement was to preserve the motion at index level. Fernstrom [14] in 1966 performed the first cervical disc arthroplasty and published his results. Metal on metal, ball and socket cervical disc prosthesis was developed by Cummins et al. [15] in late 1980s and their results were published in 1998.

Other advantages of ACDR are that it not only restores the height of the intervertebral disc but also restores the height of the foramen preventing recurrence of nerve root compression [16]. ACDR also avoids morbidity of bone graft donor site complications and allows the patients to return back to routine activities faster than ACDF [17,18]. McAfee et al. [19] in their randomised controlled trial showed a significant lower incidence of dysphagia in ACDR group compared to ACDF. ACDR also resulted in markedly lower incidence of dysphonia compared to ACDF at two years post-operative followup. ACDR also prevents other complications of ACDF like pseudoarthrosis, side effects of cervical spine immobilisation and other implant related complication of anterior cervical plating [20].

The aim of this systematic review was to evaluate the outcomes of cervical disc replacement published in PubMed indexed literature.

\section{Materials and Methods}

\subsection{Literature Search}

A literature search was carried out in medical electronic database MEDLINE. Keywords used for the search were; Cervical vertebrae, Cervical spine, Neck, Intervertebral disc, Total disc replacement, Arthroplasty, Replacement, Treatment outcome. Even though Fernstrom [14] in 1966 performed the first cervical disc arthroplasty, Ovid Medline database was searched from 1950 as Robinson and Smith [3] first described anterior cervical discectomy and fusion as early as 1955 . This search was carried out during second week of August 2012.

\subsection{Search Strategy}

Database: Ovid MEDLINE(R) $<1950$ to August Week 2 2012>
1) exp Cervical Vertebrae/(27880)
2) cervical spine.mp. (13182)
3) $\operatorname{exp~Neck/(21077)~}$
4) exp Intervertebral Disc/(9630)
5) exp Total Disc Replacement/(53)
6) exp Arthroplasty, Replacement/(27260)
7) exp Treatment Outcome/(558135)
8) 1 or 2 or 3 (51721)
9) 4 or 5 or 6 (36617)
10) 7 and 8 and 9 (262)
11) limit 10 to (english language and humans) (236)

The above search resulted in two hundred and sixty two results. Studies involving humans and English language were considered by applying additional limits, which resulted in two hundred and thirty six hits. Two authors reviewed title and abstracts of all two hundred and thirty six hits. The abstracts, which did not include the clinical and radiological outcomes of ACDR, study with only ACDF outcomes, those with duplicate publications, were discarded. The articles that satisfied the inclusion criteria were critically appraised.

\subsection{Inclusion Criteria}

Skeletally mature patients from 18 years and above.

1) All randomised controlled trials (RCTs) comparing the clinical outcomes of single level ACDF to single level ACDR;

2) Non-randomised studies assessing the clinical and radiological outcomes of ACDR.

\subsection{Exclusion Criteria}

1) Duplicate publications;

2) All studies which did not include the clinical or radiological outcomes of ACDR.

\section{Results}

Cervical disc replacement is a new technology in spinal surgery with the aim of preserving motion at the treated level without compromising the clinical outcome. Delamarter and Pradhan [21] concluded in their study that the ProDisc-C artificial cervical disc replacement was a viable surgical alternative to fusion for cervical disc degeneration and herniation with preservation of motion and alignment at treated vertebral levels without compromising the clinical outcomes. Goffin et al. [22] reported that there was ninety percent good to excellent results at one to two years after Bryan cervical disc replacement, which involved one hundred and forty six patients (103 one-level and 43 two-level) in the study.

Cepoiu-Martin et al. [23] conducted a systematic review in seven electronic databases including Medline, Embase, Cochrane library, unpublished sources and reference lists. This systematic review revealed that there were four randomised controlled trials comparing clinical outcomes of single level ACDF to single level ACDR. Safety profile of both ACDF and ACDR were similar. Authors concluded that ACDR as a surgical procedure may replace ACDF in selected patients with cervical DDD. There was weak evidence in all the studies that ACDR was superior to ACDF in treating radicular arm pain and neck pain. The authors also suggested that future studies should report change scores and change score variants in accordance with RCT guidelines so that 
credibility of conclusions can be strengthened to facilitate meta-analysis of studies.

Mummaneni et al. [16] carried out a federal drug administration (FDA) approved investigational device exemption study to show the safety and efficacy of Prestige ST cervical disc replacement. Authors carried out prospective, non-blinded, multicenter randomised control trial. Investigators carried out an analysis of five hundred and forty one patients enrolled from thirty-two different institutions. Out of five hundred and forty one patients, two hundred and seventy six patients were randomly assigned to ACDR and two hundred and sixty five patients were assigned to ACDF. Eighty percent of ACDR and seventy five percent of ACDF completed 2-year follow-up. There was a statistically significant improvement in neck pain in ACDR group at 12 months compared to ACDF group $(p<0.035)$. There was a greater improvement of neurological status in ACDR group compared to ACDF group at 12-month $(\mathrm{p}<0.006)$ and 24-month ( $<<0.005)$ follow-up, which was highly statistically significant. The authors concluded in this study that Prestige ST cervical disc replacement maintained physiological segmental motion at the index level at the end of 2-year follow-up. The ACDF group had more secondary surgeries compared to anterior cervical disc replacement group. A significant limitation of this study was that one fourth of anterior cervical discectomy and fusion patients and one fifth of anterior cervical disc replacement patients were lost to follow up at 2 years.

Nabhan et al. [24] carried out a prospective randomised controlled trial with a relatively small sample size of forty-nine patients, out of which twenty-five patients were randomised for anterior cervical disc replacement and the remaining twenty-four patients were randomised to anterior cervical discectomy and fusion. The implant used in anterior cervical disc replacement group was ProDisc-C (Synthesis spine, Umkirch, $\mathrm{CH}$ ) prosthesis while in the anterior cervical discectomy and fusion group Solis (Stryker Howmedica GmbH, Mulheim, Germany) cage with bone graft and anterior titan plate (Aesculap AG + CoKG, Tuttlingen, Germany) was used. This study showed that cervical segment motion was decreased significantly in anterior cervical discectomy and fusion group compared to anterior cervical disc replacement group. Patients had a good clinical and radiological outcome a year after the ProDisc-C replacement. ProDisc-C (Synthesis spine, Umkirch, $\mathrm{CH}$ ) prosthesis maintained segmental motion at index level at the end of one year follow-up. The clinical results of anterior cervical disc replacement group were similar to that of ACDF group at one-year follow-up. Limitation of this study was small sample size in each arm of the study population, which increases the chance of Type II error in the study.

Sasso et al. [25] conducted a randomised controlled federal drug administration approved investigational device exemption study. During this study, ACDR was carried out using Bryan cervical disc prosthesis (Medtronic Sofamor Danek, Inc., Memphis, TN). During this trial one hundred and fifteen candidates were recruited from three study centres. Fifty-six patients were randomised to anterior cervical disc replacement and the remaining fifty-nine participants were randomised for anterior cervical discectomy and fusion. 110 patients completed the 12-month follow-up while only 99 patients completed the 24-month follow-up. Authors illustrated in their study that at two-year follow-up there was a statistically significant difference in ACDR group, with improvements in the Neck Disability Index $(\mathrm{p}<0.006)$, Visual Analogue Scale (VAS) scores for neck pain $(\mathrm{p}<0.014)$ and SF-36 physical component scores, compared to ACDF group. However, there was no difference between the ACDR and ACDF groups with respect to improvement of VAS arm pain score.

Garrido et al. [26] carried out longer follow-up study on the same cohort of patients with a follow-up from twenty-four months to forty-eight months. This study showed that Bryan cervical disc prosthesis (Medtronic Sofamor Danek, Inc., Memphis, TN) continued to show favorable results compared to ACDF group. Functional outcome scores like neck disability index (NDI), Visual analogue Scales (VAS) for neck and arm pain and SF-36 scores did not deteriorate from twenty-four months follow-up to forty-eight months follow up. NDI scores at 48 months for ACDR and ACDF were 93.3\% and 82.4\% respectively. However, authors have failed to mention whether this difference was statistically significant, which is one of the limitations of the study. Authors also concluded in their study that Bryan cervical disc prosthesis (Medtronic Sofamor Danek, Inc., Memphis, TN) cohort had a lower incidence of secondary procedure compared to anterior cervical discectomy and fusion.

Murrey et al. [27] published a FDA approved investigational device exemption study comparing the safety and efficacy of anterior cervical disc replacement using ProDisc-C (Synthes spine company, L.P, West Chester, $\mathrm{PA}$ ) to anterior cervical discectomy and fusion for single level cervical degenerative disc disease in subaxial cervical spine. This was a multicenter study involving thirteen recruiting sites. Two hundred and nine patients were randomly assigned to undergo ACDR using ProDisc-C (Synthes spine company, L.P, West Chester, PA) prosthesis or ACDF. Among these 209 patients, one hundred and six patients underwent ACDF while remaining one hundred and three patients underwent ACDR using ProDisc-C (Synthes spine company, L.P, West Chester, PA) prosthesis. No statistical significant difference was found between anterior cervical discectomy and fusion and anterior cervical disc replacement groups in neck disability 
index score, SF-36 score, Visual Analogue Scale for arm and neck pain at 24 months follow-up. There was $90.9 \%$ of improvement in neurological status in the anterior cervical disc replacement group compared to $84.4 \%$ improvement in anterior cervical discectomy and fusion, which was not statistically significant. Authors concluded in the study that implantation of ProDisc-C (Synthes spine company, L.P, West Chester, PA) prosthesis was safe and effective in single level cervical degenerative disc disease and clinical outcomes were similar or slightly superior to anterior cervical discectomy and fusion. Table 1 highlight the summary of all FDA approved randomised controlled trials.

Many biomechanical studies showed that anterior cervical disc replacement preserves motion at index level and does not change the motion in adjacent motion segment or adjacent intradiscal pressure in contrast to anterior cervical discectomy and fusion [28-31]. Park et al. [32] carried out a quantitative analysis and comparative analysis of motion patterns using validated computer assisted method to compare the cervical spine kinematics after anterior cervical disc replacement versus anterior cervical discectomy and fusion. Authors noticed that angular motion was significantly increased in superior adjacent segment in anterior cervical discectomy and fusion compared to anterior cervical disc replacement. Digital radiographs from a prospective randomised controlled trial were included for kinematic assessment of cervical spine by Sasso et al. [20]. During this study functional spinal unit motion parameters like, range of motion, translation and centre of rotations were calculated between anterior cervical discectomy and fusion group versus Bryan disc replacement group. This study showed that there was increased antero posterior translation at the cephalad level to the anterior cervical discectomy and fusion whereas in Bryan disc replacement group normal antero-posterior translation was maintained at the cephalad level to the disc replacement. Authors concluded in this study that Bryan disc replacement might delay symptomatic adjacent segment disease by preserving pre operative kinematics at adjacent segment.

Anakwenze et al. [33] carried out a prospective RCT comparing sagittal cervical alignment in ACDF and
ACDR. In both the groups, lordosis was increased at index level, cranial, and in total cervical alignment while lordosis was decreased at the caudal adjacent level in both groups. Quan et al. [34] published the longest follow-up study, so far available in the literature about Bryan cervical disc (Medtronic Sofamor Danek Inc., Memphis, TN) replacement. This study was a prospective analysis of thirty patients who under went Bryan cervical disc (Medtronic Sofamor Danek Inc., Memphis, $\mathrm{TN})$ replacement. Only twenty-one patients were available for follow-up at eight years, nine patients were lost to follow up. At eight years follow-up Bryan cervical disc (Medtronic Sofamor Danek Inc., Memphis, TN) replacement maintained favourable clinical and radiological outcome. The authors concluded in their study that heterotropic ossification was a matter of concern as time progressed. Increasing incidence of heterotropic ossification can cause restricted range of movement at the index procedure as time progresses.

The Prestige LP $^{\circledR}$ (Medtronic Sofamor Danek) cervical disc prosthesis which was born fifteen years ago, radically differs from its predecessors in that acute fixation was achieved by a set of rails that are placed on the intervertebral contact surface. This not only eliminates the anterior profile of the device but also simplifies implantation and allows for unrestricted multilevel implantation [1]. There is only one study in the literature to date that has exclusively assessed the clinical and radiological outcomes of Prestige LP $^{\circledR}$ (Medtronic Sofamor Danek) cervical disc replacement [35], which was the most modified version of Prestige Cervical Disc prosthesis. Peng et al. [35] conducted a prospective study to evaluate the clinical outcomes of Prestige LP $^{\circledR}$ (Medtronic Sofamor Danek) cervical disc replacement and compared these results to retrospectively collected data of anterior cervical discectomy and fusion from the same institution. This study showed that there was no significant difference between Prestige LP ${ }^{\circledR}$ (Medtronic Sofamor Danek) cervical disc replacement group and anterior cervical discectomy and fusion group. Authors concluded that there was a good clinical outcome and at 2 years follow-up the implanted Prestige LP ${ }^{\circledR}$ (Medtronic Sofamor Danek) cervical

Table 1. Summary of FDA approved randomised controlled trials.

\begin{tabular}{llccc}
\hline Author & Type of ACDR & $\begin{array}{c}\text { Number of patients } \\
\text { randomised for ACDR }\end{array}$ & $\begin{array}{c}\text { Number of patients } \\
\text { randomised for ACDF }\end{array}$ & $\begin{array}{c}\text { Duration of Follow-up } \\
\text { (in months) }\end{array}$ \\
\hline Mummaneni et al. [16] & Prestige ST disc & 276 & 265 & 24 \\
Nabhan et al. [24] & ProDisc-C & 24 & 25 & 12 \\
Sasso et al. [25] & Bryan cervical disc & 56 & 59 & 24 \\
Garrido et al. [26] & Bryan cervical disc & 56 & 59 & 48 \\
Murrey et al. [27] & ProDisc-C & 103 & 109 & 24 \\
\hline
\end{tabular}


disc prosthesis maintained physiological motion.

\section{Conclusion}

In summary, cervical disc degeneration is often asymptomatic but some may present as neck and arm pain associated with radiculopathy and/or myelopathy. Untreated cervical degenerative disc disease might decrease, stabilise or worsen. Initially symptoms of cervical degenerative disc disease are typically treated with conservative, non-surgical management for a period of two to six months. ACDF has been regarded as gold standard of treatment for disc herniation and DDD refractory to conservative management for a long time. ACDF can result in symptomatic adjacent segment disease, other morbidities like pseudoarthrosis, donor site morbidity and instrumentation related complications. This led surgeons to think towards an alternative procedure like anterior cervical disc replacement. Anterior cervical disc replacement is a relatively new technology in spinal surgery with the aim of preserving motion at the index level without compromising the clinical outcome. There are several short and intermediate term follow-up studies to prove the safety and efficacy of ACDR with satisfactory clinical and radiological outcomes. Majority of studies in the literature showed that ACDR might be superior to ACDF in treating cervical DDD with arm and neck pain. However, more intermediate to long-term follow-up studies are needed to prove the safety and efficacy of ACDR without compromising clinical and radiological outcomes.

\section{REFERENCES}

[1] V. C. Traynelis, "The Prestige Cervical Disc Replacement,” The Spine Journal, Vol. 4, No. 6S, 2004, pp. 310S314S. doi:10.1016/j.spinee.2004.07.025

[2] H. H. Bohlman, S. E. Emery, D. B. Goodfellow and P. K. Jones, "Robinson Anterior Cervical Discectomy and Arthrodesis for Cervical Radiculopathy: Long-Term Follow-Up of One Hundred and Twenty-Two Patients," The Journal of Bone and Joint Surgery (American), Vol. 75, No. 9, 1993, pp. 1298-1307.

[3] R. A. Robinson and G. W. Smith, “Anterolateral Cervical Disc Removal and Interbody Fusion for Cervical Disc Syndrome," Bulletin of the Johns Hopkins Hospital, Vol. 95, No. 1, 1955, pp. 223-224.

[4] J. C. Eck, S. C. Humphreys, T. H. Lim, S. T. Jeong, J. G. Kim, S. D. Hodges and H. S. An, "Biomechanical Study on the Effect of Cervical Spine Fusion on Adjacent-Level Intradiscal Pressure and Segmental Motion,” Spine, Vol. 27, No. 22, 2002, pp. 2431-2434. doi:10.1097/00007632-200211150-00003

[5] S. Matsunaga, S. Kabayama, T. Yamamoto, K. Yone, T. Sakou and K. Nakanishi, "Strain on Intervertebral Discs after Anterior Cervical Decompression and Fusion," Spine, Vol. 24, No. 7, 1999, pp. 670-675.

\section{doi:10.1097/00007632-200211150-00003}

[6] C. Wigfield, S. Gill, R. Nelson, I. Langdon, N. Metcalf and J. Robertson, "Influence of an Artificial Cervical Joint Compared with Fusion on Adjacent-Level Motion in the Treatment of Degenerative Cervical Disc Disease," Journal of Neurosurgery, Vol. 96, No. 1S, 2002, pp. 1721.

[7] A. S. Hilibrand, G. D. Carlson, M. A. Palumbo, P. K. Jones and H. H. Bohlman, "Radiculopathy and Myelopathy at Segments Adjacent to the Site of a Previous Anterior Cervical Arthrodesis," Journal of Bone and Joint Surgery (American), Vol. 81, No. 4, 1999, pp. 519-528.

[8] H. M. Heneghan and J. P. McCabe, "Use of Autologous Bone Graft in Anterior Cervical Decompression: Morbidity \& Quality of Life Analysis,” BMC Musculoskeletal Disorders, Vol. 10, No. 1, 2009, p. 158. doi:10.1186/1471-2474-10-158

[9] R. D. Guyer and D. D. Ohnmeiss, "Intervertebral Disc Prosthesis,” Spine, Vol. 28, No. 15S, 2003, pp. S15-S23. doi:10.1097/01.BRS.0000076843.59883.E1

[10] R. B. Delamarter, D. M. Fribourg, L. E. Kanim and H. Bae, "ProDisc Artificial Total Lumbar Disc Replacement: Introduction and Early Results from the United States Clinical Trial,” Spine, Vol. 28, No. 20, 2003, pp. S167S175. doi:10.1097/01.BRS.0000092220.66650.2B

[11] F. M. Phillips, G. Carlson, S. E. Emery and H. H. Bohlman, "Anterior Cervical Pseudarthrosis: Natural History and Treatment," Spine, Vol. 22, No. 14, 1997, pp. 15851589. doi:10.1097/00007632-199707150-00012

[12] B. W. Wipperman, H. E. Schratt, S. Steeg and H. Tscherne, "Complications of Spongiosa Harvesting of the Iliac Crest: A Retrospective Analysis of 1191 Cases,” Der Chirurg, Vol. 68, No. 12, 1997, pp. 1286-1291.

[13] J. A. Turner, M. Ersek, L. Herron, J. Haselkorn, D. Kent, M. A. Ciol and R. Deyo, "Patient Outcomes after Lumbar Spinal Fusions," The Journal of the American Medical Association, Vol. 268, No. 7, 1992, pp. 907-911. doi:10.1001/jama.1992.03490070089049

[14] U. Fernstrom, "Arthroplasty with Intercorporeal Endoprosthesis in Herniated Disc and in Painful Disc," Acta Chirurgica Scandinavica: Supplementum, Vol. 357, 1966, pp. 154-159.

[15] B. H. Cummins, J. T. Robertson and S. S. Gill, "Surgical Experience with an Implanted Artificial Cervical Joint," Journal of Neurosurgery, Vol. 88, No. 6, 1998, pp. 943948. doi:10.3171/jns.1998.88.6.0943

[16] P. V. Mummaneni, J. K. Burkus, R. W. Haid, V. C. Traynelis and T. A. Zdeblick, "Clinical and Radiographic Analysis of Cervical Disc Arthroplasty Compared with Allograft Fusion: A Randomized Controlled Clinical Trial,” Journal of Neurosurgery: Spine, Vol. 6, No. 3, 2007, pp. 198-209. doi:10.3171/spi.2007.6.3.198

[17] J. S. Silber, D. G. Anderson, S. D. Daffner, B. T. Brislin, J. M. Leland, A. S. Hilibrand, A. R. Vaccaro and T. J. Albert, "Donor Site Morbidity after Anterior Iliac Crest Bone Harvest for Single-Level Anterior Cervical Discectomy and Fusion,” Spine, Vol. 28, No. 2, 2003, pp. 134139. doi:10.1097/00007632-200301150-00008 
[18] T. A. St. John, A. R. Vaccaro, A. P. Sah, M. Schaefer, S. C. Berta, T. Albert and A. Hilibrand, "Physical and Monetary Costs Associated with Autogenous Bone Graft Harvesting," American Journal of Orthopaedics, Vol. 32, No. 1, 2003, pp. 18-23.

[19] P. C. McAfee, A. Cappuccino, B. W. Cunningham, J. G. Devine, F. M. Phillips, J. J. Regan, T. J. Albert and J. E. Ahrens, "Lower Incidence of Dysphagia with Cervical Arthroplasty Compared with ACDF in a Prospective Randomized Clinical Trial," Journal of Spinal Disorders and Techniques, Vol. 23, No. 1, 2010, pp. 1-8. doi:10.1097/BSD.0b013e31819e2ab8

[20] R. C. Sasso and N. M. Best, "Cervical Kinematics after Fusion and Bryan Disc Arthroplasty,” Journal of Spinal Disorders and Techniques, Vol. 21, No. 1, 2008, pp. 1921. doi:10.1097/BSD.0b013e3180500778

[21] R. B. Delamarter and B. B. Pradhan, "Indications for Cervical Spine Prostheses, Early Experiences with ProDisc-C in the USA,” Spine Art, Vol. 1, 2004, pp. 7-9.

[22] J. Goffin, F. Van Calenbergh, J. van Loon, A. Casey, P. Kehr, K. Liebig, B. Lind, C. Logroscino, R. Sgrambiglia and V. Pointillart, "Intermediate Follow-Up after Treatment of Degenerative Disc Disease with Bryan Cervical Disc Prosthesis: Single-Level and Bi-Level,” Spine, Vol. 28, No. 24, 2003, pp. 2673-2678. doi:10.1097/01.BRS.0000099392.90849.AA

[23] M. Cepoiu-Martin, P. Faris, D. Lorenzetti, E. Prefontaine, T. Noseworthy and L. Sutherland, "Artificial Cervical Disc Arthroplasty: A Systematic Review,” Spine, Vol. 36, No. 25, 2011, pp. E1623-E1633. doi:10.1097/BRS.0b013e3182163814

[24] A. Nabhan, F. Ahlhelm, K. Shariat, T. Pitzen, O. Steimer, W. I. Steudel and D. Pape, "The ProDisc-C Prosthesis. Clinical and Radiological Experience 1 Year after Surgery,” Spine, Vol. 32, No. 18, 2007, pp. 1935-1941. doi:10.1097/BRS.0b013e3182163814

[25] R. C. Sasso, J. D. Smucker, R. J. Hacker and J. G. Heller, "Artificial Disc versus Fusion: A Prospective, Randomised Study with 2-Year Follow-Up on 99 Patients,” Spine, Vol. 32, No. 26, 2007, pp. 2933-2940. doi:10.1097/BRS.0b013e31815d0034

[26] B. J. Garrido, T. A. Taha and R. C. Sasso, "Clinical Outcomes of Bryan Cervical Disc Arthroplasty a Prospective, Randomized, Controlled, Single Site Trial with 48-Month Follow-Up," Journal of Spinal Disorders and Techniques, Vol. 23, No. 6, 2010, pp. 367-371. doi:10.1097/BRS.0b013e31815d0034

[27] D. Murrey, M. Janssen, R. Delamarter, J. Goldstein, J. Zigler, B. Tay and B. Darden, "Results of the Prospective, Randomized, Multi-Center Food and Drug Administration Investigational Device Exemption Study of the Pro-
Disc-C Total Disc Replacement versus Anterior Discectomy and Fusion for the Treatment of 1-Level Symptomatic Cervical Disc Disease,” The Spine Journal, Vol. 9, No. 4, 2009, pp. 275-286.

doi:10.1016/j.spinee.2008.05.006

[28] J. T. Robertson, S. M. Papadopoulos and V. C. Traynelis, "Assessment of Adjacent Segment Disease in Patients Treated with Cervical Fusion or Arthroplasty: A Prospective 2-Year Study,” Journal of Neurosurgery: Spine, Vol. 3, No. 6, 2005, pp. 417-423. doi:10.1016/j.spinee.2008.05.006

[29] A. E. Dmitriev, B. W. Cunningham, N. Hu, G. Sell, F. Vigna and P. C. McAfee, "Adjacent Level Intradiscal Pressure and Segmental Kinematics Following a Cervical Total Disc Arthroplasty: An in Vitro Human Cadaveric Model,” Spine, Vol. 30, No. 10, 2005, pp. 1165-1172. doi:10.1097/01.brs.0000162441.23824.95

[30] C. A. Reitman, J. A. Hipp, L. Nguyen and S. I. Esses, "Changes in Segmental Intervertebral Motion Adjacent to Cervical Arthrodesis: A Prospective Study,” Spine, Vol. 29, No. 11, 2004, pp. E221-E226. doi:10.1097/01.brs.0000162441.23824.95

[31] C. Wigfield, S. Gill, R. Nelson, I. Langdon, N. Metcalf and J. Robertson, "Influence of an Artificial Cervical Joint Compared with Fusion on Adjacent-Level Motion in the Treatment of Degenerative Cervical Disc Disease," Journal of Neurosurgery, Vol. 96, No. 1S, 2002, pp. 1721.

[32] D. K. Park, E. L. Lin and F. M. Phillips, "Index and Adjacent Level Kinematics after Cervical Disc Replacement and Anterior Fusion: In Vivo Quantitative Radiographic Analysis,” Spine, Vol. 36, No. 9, 2011, pp. 721-730. doi:10.1097/01.brs.0000162441.23824.95

[33] O. A. Anakwenze, J. D. Auerbach, A. H. Milby, B. S. Lonner and R. A. Balderston, "Sagittal Cervical Alignment after Cervical Disc Arthroplasty and Anterior Cervical Discectomy and Fusion: Results of a Prospective, Randomized, Controlled Trial,” Spine, Vol. 34, No. 19, 2009, pp. 2001-2007. doi:10.1097/BRS.0b013e3181b03fe6

[34] G. M. Quan, J. M. Vital, S. Hansen and V. Pointillart, "Eight-Year Clinical and Radiological Follow-Up of the Bryan Cervical Disc Arthroplasty,” Spine, Vol. 36, No. 8, 2011, pp. 639-646. doi:10.1097/BRS.0b013e3181b03fe6

[35] C. W. Peng, W. M. Yue, A. Basit, C. M. Guo, B. P. Tow, J. L. Chen, M. Nidu, W. Yeo and S. B. Tan, "Intermediate Results of the Prestige LP Cervical Disc Replacement: Clinical and Radiological Analysis with Minimum TwoYear Follow-Up,” Spine, Vol. 36, No. 2, 2011, pp. E105E111. doi:10.1097/BRS.0b013e3181b03fe6 